\title{
Efeito do ácido giberélico e diferentes aminoácidos sobre as atividades da sintetase da glutamina e sintase do glutamato e sobre o crescimento de frutos de soja
}

\author{
RONALDO DO NASCIMENTO ${ }^{1,3}$ e PAULO R. MOSQUIM ${ }^{2}$
}

(recebido: 30 de outubro de 2002; aceito: 23 de outubro de 2003)

\begin{abstract}
Effect of the gibberellic acid and different aminoacids on the activities of glutamine synthetase and glutamate synthase, and on growth of soybean fruits). The work had as objective to evaluate the effect of different aminoacids and of the gibberelic acid (GA) on the activity of glutamine synthetase (GS) and glutamate synthase (GOGAT) and the growth of soybean fruits. Immature fruits were cultivated with different paclobutrazol (PBZ) concentrations, inhibitor gibberellin synthesis, which it inhibited the growth of the fruits in up to $80 \%$. In a second stage, the effect of the GA was evaluated on the growth of the soybean fruits cultivated with PBZ. The growth regulator reestablished the growth of the cultivated fruits with $0,034 \mathrm{mM} \mathrm{PBZ}$. However, with $0,85 \mathrm{mM} \mathrm{PBZ}$ it was not obtained the same positive effect, indicating a possible level phytotoxic. Following fruits was cultivated during eight days, with glutamine, asparagine or allantoine, with or without GA, after which the enzymatic activities were determined. The enzymes of assimilation of the nitrogen went more active under presence of the allantoine. The GA inhibited the GS activity and it stimulated the of Fd-GOGAT and of NADH-GOGAT. The Fd-GOGAT activity went superior of the NADH-GOGAT, perhaps due to reduced ferredoxin in the cultivated fruits under constant illumination, advent of the photosynthetic. The results indicate that, probably, gibberellins are involved in the growth of immature fruits of soybean and in regulation enzymatic activities of the GS and GOGAT in that fruits.
\end{abstract}

Key words - aminoacids, gibberellin, growth regulator, nitrogen, paclobutrazol

RESUMO - (Efeito do ácido giberélico e diferentes aminoácidos sobre as atividades da sintetase da glutamina e sintase do glutamato e sobre o crescimento de frutos de soja). O trabalho teve como objetivo avaliar o efeito de diferentes aminoácidos e do ácido giberélico (GA) sobre a atividade da glutamina sintetase (GS) e da glutamato sintase (GOGAT) e o crescimento de frutos de soja. Frutos imaturos foram cultivados com diferentes concentrações de paclobutrazol (PBZ), inibidor da biossíntese de giberelinas, o qual inibiu o crescimento dos frutos em até $80 \%$. Em seguida foi avaliado o efeito do GA sobre o crescimento dos frutos de soja cultivados com PBZ. O regulador de crescimento restabeleceu o crescimento dos frutos cultivados com 0,034 mM de PBZ. Entretanto, com 0,85 mM de PBZ não se obteve o mesmo efeito positivo, indicando um possível nível fitotóxico. Posteriormente os frutos foram cultivados durante oito dias com glutamina, asparagina ou alantoína, na presença ou não de GA, após o que determinaram-se as atividades enzimáticas. As enzimas de assimilação do nitrogênio foram mais ativas na presença da alantoína. O GA inibiu a atividade da GS e estimulou as da Fd-GOGAT e da NADH-GOGAT. A atividade da FdGOGAT foi superior à da NADH-GOGAT, talvez devido à ferredoxina reduzida presente nos frutos cultivados sob iluminação constante, advinda da atividade fotossintética. Os resultados obtidos permitem concluir que giberelinas, provavelmente, estão envolvidas no crescimento de frutos imaturos de soja e na regulação da atividade das enzimas GS e GOGAT nesses frutos.

Palavras-chave - aminoácidos, giberelina, nitrogênio, paclobutrazol, regulador do crescimento

\section{Introdução}

As duas principais formas de nitrogênio absorvidas pelas plantas superiores são o nitrato e o amônio. $\mathrm{O}$ nitrato absorvido pelas raízes, pode ser armazenado nos vacúolos, reduzido a amônio ou translocado para a parte

\footnotetext{
1. Universidade Federal de Pelotas, Instituto de Biologia, Departamento de Botânica, Campus universitário, 96910-900 Pelotas, RS, Brasil.

2. Universidade Federal de Viçosa, Centro de Ciências Biológicas e da Saúde, Departamento de Biologia Vegetal, Campus universitário, 36571-000 Viçosa, MG, Brasil.

3. Autor para correspondência: ronascim@ufpel.tche.br
}

aérea, onde pode ser metabolizado a amônio (Glass et al. 2002).

As atividades coordenadas da glutamina sintetase (GS) e da glutamato sintase (GOGAT) possibilitam a assimilação do amônio liberado pela redutase do nitrito. A GS ocupa uma posição central no metabolismo do nitrogênio nas plantas, pois é responsável pela assimilação inicial do amônio. Essa enzima catalisa a incorporação do amônio em glutamato, formando glutamina. A GOGAT, por sua vez, catalisa a transferência redutiva do nitrogênio amida da glutamina para a posição a-ceto do 2-oxoglutarato, o que resulta na formação de duas moléculas de glutamato (Gregerson et al. 1993). 
O produto da atuação do ciclo GS/GOGAT, o glutamato, pode servir como substrato para a biossíntese de vários metabólitos nitrogenados, os quais são precursores de proteínas e ácidos nucléicos (Schuller etal.1986).

Devido à importância da GS e GOGAT na assimilação do nitrogênio nas plantas, Rhodes et al. (1975) destacam o fato de que essas enzimas são controladas por vários mecanismos regulatórios. Peat \& Tobin (1996) verificaram em cevada que as atividades dessas enzimas variaram em função da fonte de nitrogênio utilizada. Chanda et al. (1998) obtiveram resultados com plântulas de mostarda, mostrando que o ácido giberélico $\left(\mathrm{GA}_{3}\right)$ estimulou a atividade da GS na raiz e no coleóptilo e inibiu nos cotilédones. Isso indica que a atividade das enzimas GS e GOGAT pode apresentar algum tipo de regulação hormonal.

Tendo em vista que a síntese da glutamina ocorre via reação da GS e sendo ela o substrato para a GOGAT, a GS desempenharia um papel central no metabolismo do nitrogênio. Há evidências de que a GS poderia estar sujeita a diversos tipos de controles, dentre os quais estão a repressão e ativação em resposta a diferentes aminoácidos e fitormônios (Chanda et al. 1998).

As giberelinas são responsáveis por várias funções fisiológicas importantes no desenvolvimento das plantas superiores (Hooley 1994, Lange 1998). Das funções mais conhecidas, destacam-se a mobilização de reserva em sementes de cereais em germinação e a promoção do alongamento do caule em algumas espécies. Dependendo da planta, as giberelinas também podem ser necessárias à expansão foliar, à indução floral, à biossíntese de antocianinas (Stephen et al. 1997) e ao desenvolvimento de frutos imaturos (Graebe 1987, Garcia-Martinez et al. 1987, Van Huizen et al. 1997).

Barendse et al. (1986) avaliaram o crescimento de frutos e sementes de Arabidopsis deficientes em giberelinas. Eles observaram que essa deficiência não influenciou o crescimento das sementes; no entanto, o crescimento dos frutos foi afetado. Santes et al. (1995) observaram que as giberelinas estão envolvidas no crescimento de frutos de ervilha.

Tendo em vista a importância das enzimas glutamina sintetase e glutamato sintase para o metabolismo do nitrogênio, processo fundamental para o acúmulo de proteínas em sementes de soja, e da escassez de informações sobre os mecanismos de controle da atividade dessas enzimas durante o crescimento inicial de frutos de soja, neste trabalho procurou-se avaliar o efeito do ácido giberélico e de diferentes aminoácidos sobre a atividade da glutamina sintetase e glutamato sintase e sobre o crescimento de frutos imaturos de soja.

\section{Material e métodos}

Sementes de soja [Glycine $\max$ (L.) Merril cv. UFV 16], fornecidas pelo Departamento de Fitotecnia da Universidade Federal de Viçosa, foram semeadas em vasos de polietileno com capacidade para três litros, contendo areia lavada. As plântulas obtidas foram mantidas em casa de vegetação sob condições naturais de temperatura, umidade relativa e luminosidade durante o período de outubro de 1997 a dezembro de 1998.

Quando as plântulas apresentavam o primeiro trifólio completamente expandido, procedeu-se a um desbaste, deixando-se apenas duas por vaso. Essas foram irrigadas, sempre que necessário, com água e, três vezes por semana, foram aplicados $250 \mathrm{~mL}$ de uma solução nutritiva completa de Hoagland (Hoagland \& Arnon 1938). As plantas permaneceram nessas condições até que os frutos apresentassem massa fresca aproximada de $50 \mathrm{mg}$, quando foram transferidas ao laboratório visando à instalação do sistema de cultivo dos frutos de soja em condições semiassépticas.

O cultivo in vitro seguiu a metodologia descrita por Mosquim \& Sodek (1991). No laboratório, as plantas foram completamente desfolhadas, retirados os frutos em excesso, deixando-se apenas os frutos com o tamanho adequado ligados à base dos pecíolos. Em seguida os caules foram imersos em bandejas com água destilada sendo cortados segmentos dos caules com $60 \mathrm{~mm}$ de comprimento e que continham um fruto. Após rigorosa seleção quanto a homogeneidade dos explantes, os mesmos tiveram suas bases mergulhadas em frascos de vidro com capacidade para $10 \mathrm{~mL}$ contendo $6,5 \mathrm{~mL}$ dos meios de cultivo em cada frasco.

A cada 48 horas, cerca de $2 \mathrm{~mm}$ do segmento de caule foi cortado em sua base para desobstruir algum vaso que poderia estar bloqueado. No quarto dia de cultivo, os meios foram trocados para evitar exaustão de minerais ou substâncias orgânicas.

O meio de cultivo líquido foi preparado segundo Chandler et al. (1983), para os macronutrientes, exceto o nitrogênio, e Thompson et al. (1977), para os micronutrientes. Os íons acompanhantes do nitrogênio retirados da fórmula original foram adicionados juntamente com outros sais utilizados. Como fontes exclusivas de nitrogênio, utilizou-se glutamina ou asparagina ou alantoína, sempre na concentração final de $85,7 \mathrm{mM}$ de nitrogênio e como fonte de carbono, a sacarose, na concentração de $5 \%$. O pH dos meios de cultivo foi ajustado para 5,0. Os explantes foram mantidos sob irradiância contínua de aproximadamente $80 \mu \mathrm{mol} \cdot \mathrm{m}^{-2} \cdot \mathrm{s}^{-1}$ e temperatura de $25 \pm 2{ }^{\circ} \mathrm{C}$.

Numa etapa inicial avaliaram-se o efeito do ácido giberélico e paclobutrazol [(2RS, 3RS)-1-(4-clorofenil)-4,4- 
dimetil-2-(1,2,4-triazol-1-il)-pentano-3-ol], um inibidor da biossíntese de giberelinas, sobre o crescimento dos frutos. O paclobutrazol foi utilizado isoladamente nas concentrações de $0 \mathrm{mM} ; 0,034 \mathrm{mM} ; 0,170 \mathrm{mM} ; 0,340 \mathrm{mM}$; e $0,850 \mathrm{mM}$. Numa segunda etapa, foi avaliado o efeito da aplicação de ácido giberélico $\left(\mathrm{GA}_{3}\right)$ sobre o crescimento dos frutos cultivados com paclobutrazol. Utilizaram-se, então, o paclobutrazol isoladamente nas concentrações de $0,034 \mathrm{mM} \mathrm{e} 0,85 \mathrm{mM} \mathrm{e}$ ácido giberélico em $10^{-4} \mathrm{M}$, além das combinações entre $0,034 \mathrm{mM}$ e $0,85 \mathrm{mM}$ do inibidor e $10^{-4} \mathrm{M}$ de $\mathrm{GA}_{3}$. Nesses experimentos utilizou-se a glutamina como fonte de nitrogênio. Em seguida foram utilizadas as fontes exclusivas de nitrogênio glutamina ou asparagina ou alantoína. Após oito dias de cultivo, determinaram-se o comprimento e a largura dos frutos com um paquímetro. A massa fresca total dos frutos foi determinada em uma balança analítica. Em seguida, os frutos foram transferidos para uma estufa controlada para $75^{\circ} \mathrm{C}$, onde permaneceram até atingir peso constante, para determinação da massa seca. Plantas intactas foram mantidas na casa de vegetação para obtenção de controles, tendo em vista comparações entre o comportamento dos frutos cultivados "in vitro" com frutos cultivados "in situ" nos dias da montagem (controle D0) e desmontagem (controle D8) dos experimentos.

Numa etapa posterior, verificou-se o efeito das três fontes de nitrogênio e do ácido giberélico sobre a atividade das enzimas GS e GOGAT dependente de NADH ou de ferredoxina. Para isso, explantes dos frutos foram cultivados com glutamina ou asparagina ou alantoína, como fontes exclusivas de nitrogênio, com ou sem $10^{-4} \mathrm{M}$ de ácido giberélico. O período de cultivo foi de oito dias, após o qual avaliaram-se as atividades enzimáticas nos frutos sempre no mesmo horário no início da manhã.

Para determinação de todos os ensaios enzimáticos, foi preparado um extrato bruto dos frutos, macerando-os em almofariz com pistilo (previamente resfriados). $\mathrm{O}$ meio de extração seguiu a metodologia de Haüssler et al. (1994) com algumas modificações, sendo constituído de tampão Tris-HCl (100 mM, pH 7,8), $\mathrm{MgSO}_{4}(2,5 \mathrm{mM}), \mathrm{KCl}(25 \mathrm{mM})$, DTT (1 mM), $\beta$-mercaptoetanol $(1 \%, \mathrm{v} / \mathrm{v})$, EDTA $(0,25 \mathrm{mM})$, Triton X-100 $(0,5 \%)$ e glicerol $(2 \%, \mathrm{v} / \mathrm{v})$. Foram utilizados cinco $\mathrm{mL}$ de tampão de extração por grama de tecido dos frutos. A temperatura de extração foi mantida entre 0 e $4{ }^{\circ} \mathrm{C}$, utilizando-se banho de gelo. $\mathrm{O}$ homogeneizado assim obtido foi centrifugado a $15000 \mathrm{~g}$, durante quinze minutos, a $4{ }^{\circ} \mathrm{C}$. Alíquotas do sobrenadante $(50 \mu \mathrm{L}$ para a GS, $100 \mu \mathrm{L}$ para a Fd-GOGAT e $300 \mu \mathrm{L}$ para a NADH-GOGAT) foram imediatamente usadas para as avaliações das atividades enzimáticas.

A atividade da GS foi determinada pela formação de glutamil-hidroxamato e quantificada com cloreto férrico acidificado. $\mathrm{O}$ ensaio foi realizado conforme Rhodes et al. (1975), modificado por Tonin (1988) e Junghans \& Mosquim (1995).

A atividade da NADH-GOGAT foi quantificada por meio da mensuração do NADH oxidado formado. O ensaio foi realizado seguindo-se o método proposto por Rhodes et al. (1975), modificado por Tonin (1988) e Junghans \& Mosquim (1995). Para a determinação da atividade da Fd-GOGAT, metil viologênio reduzido foi usado como substrato (Haüssler et $a$ l. 1994).

Neste trabalho foi utilizado um delineamento experimental inteiramente casualizado, em que cada explante se constituiu numa repetição. Para as determinações das massas fresca e seca, comprimento e largura, cada tratamento foi composto por seis repetições e para as atividades enzimáticas, quatro repetições. As médias foram comparadas pelo teste de Tukey, em nível de $5 \%$ de probabilidade.

\section{Resultados e Discussão}

O aumento na concentração de paclobutrazol no meio de cultivo acarretou uma redução expressiva no comprimento (figura 1A), na largura (figura 1B) e na produção de massa seca (figura 1C) dos frutos, em relação ao controle sem fitorregulador. A redução mais acentuada ocorreu com a massa seca, que chegou a 80\%; o comprimento e largura diminuíram em 64\% e $67 \%$, respectivamente, conforme a concentração de PBZ aumentava. Uma possível explicação para esse efeito inibitório seria que o paclobutrazol tenha inibido a enzima oxidase do ent-caureno (Garcia-Martinez et al. 1987), e, consequentemente, as etapas oxidativas do ent-caureno a ácido ent-caurenóico teriam sido bloqueadas, o que pode ter inibido a biossíntese de giberelinas nos frutos de soja, levando a uma possível diminuição dos seus níveis endógenos e à conseqüente redução do crescimento dos frutos.

Resultados semelhantes foram também observados em frutos jovens de ervilha, por Rodrigo et al. (1997) e Garcia-Martinez et al. (1987). Foi verificado por esses autores que o $\mathrm{GA}_{3}$, uma das giberelinas mais ativas no crescimento dos frutos, teve seus níveis endógenos acentuadamente reduzidos pelo paclobutrazol, e, em conseqüência, o crescimento dos frutos foi drasticamente inibido.

O paclobutrazol na concentração de $0,85 \mathrm{mM}$, causou inibição no crescimento dos frutos nos primeiros dias após sua aplicação (dados não mostrados). Isso, provavelmente, ocorreu devido a sua fácil translocação até os frutos, uma vez que essa substância é facilmente transportada via xilema (Wang et al. 1986, Sterrett 1985).

A figura 2 mostra que a aplicação de $\mathrm{GA}_{3} \mathrm{em}$ frutos de soja sob efeito do paclobutrazol acarretou um crescimento igual ou superior ao controle D8. Quando os explantes foram cultivados com paclobutrazol em maior concentração, ou seja, de 

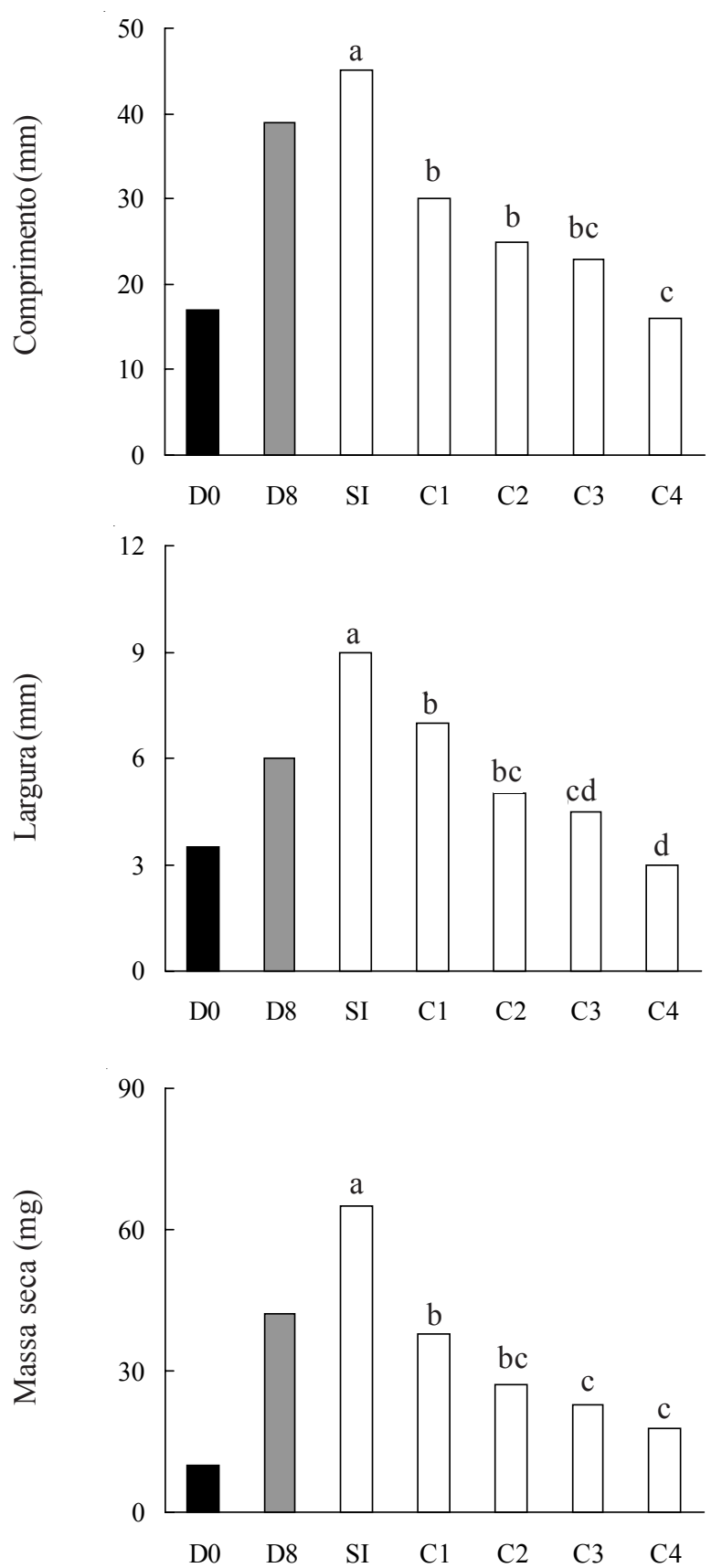

Figura 1. Efeito de diferentes concentrações de paclobutrazol (PBZ) sobre o comprimento (A), largura (B) e produção de massa seca $(\mathrm{C})$ de frutos de soja. D0 (controle dia 0), D8 (controle dia 8), SI (sem PBZ), C1 (PBZ 0,034 mM), C2 (PBZ $0,17 \mathrm{mM})$, C3 (PBZ 0,34 mM) e C4 (PBZ 0,85 mM). Médias seguidas de uma mesma letra não diferem entre si pelo teste de Tukey $(\mathrm{P} \leq 0,05)$.

Figure 1. Effect of different paclobutrazol (PBZ) concentrations on the length (A), width (B) and dry matter (C) in soybean fruit. D0 (control day 0), D8 (control day 8), SI (without PBZ), C1 (PBZ $0.034 \mathrm{mM}$ ), C2 (PBZ $0.17 \mathrm{mM}$ ), C3 (PBZ $0.34 \mathrm{mM}$ ) e C4 (PBZ $0.85 \mathrm{mM}$ ). Means followed by same letters are not significantly different by Tukey test $(\mathrm{P} \leq 0.05)$.
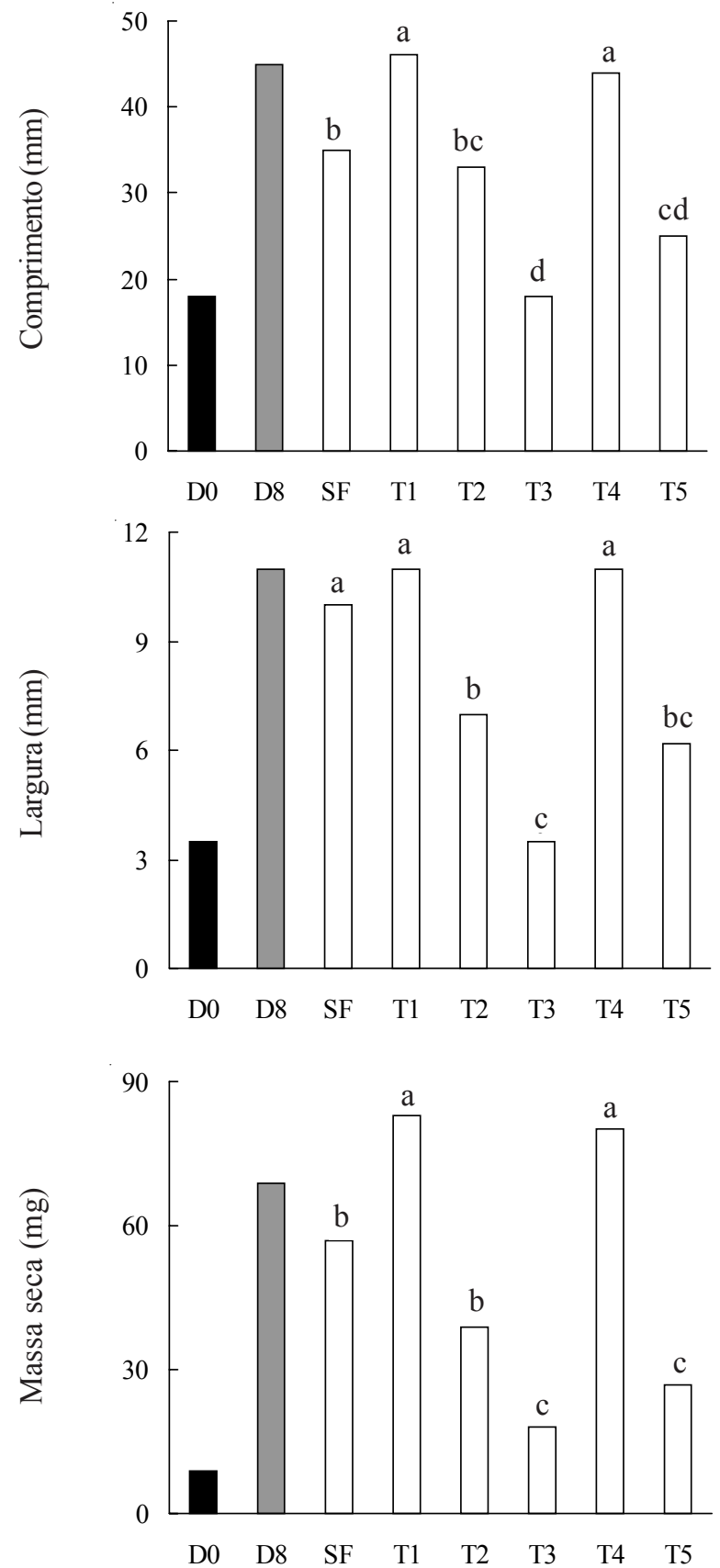

C

Figura 2. Efeito do paclobutrazol (PBZ) e ácido giberélico $\left(\mathrm{GA}_{3}\right)$ sobre o comprimento (A), largura (B) e massa seca (C) de frutos de soja. D0 (controle dia 0), D8 (controle dia 8), SF (sem PBZ e GA $)_{3}$ ), T1 (GA $\left.10^{-4} \mathrm{M}\right)$, T2 (PBZ 0,034 mM), T3 (PBZ 0,85 mM), T4 (PBZ 0,034 mM + GA $\left.10^{-4} \mathrm{M}\right)$ e T5 (PBZ $\left.0,85 \mathrm{mM}+\mathrm{GA}_{3} 10^{-4} \mathrm{M}\right)$. Médias seguidas de uma mesma letra não diferem entre si pelo teste de Tukey $(\mathrm{P} \leq 0,05)$.

Figure 3. Effect of the paclobutrazol (PBZ) and gibberellic acid $\left(\mathrm{GA}_{3}\right)$ concentrations on the length $(\mathrm{A})$, width $(\mathrm{B})$ and dry matter (C) in soybean fruit. D0 (control day 0 ), D8 (control day 8), SF (without PBZ and $\left.\mathrm{GA}_{3}\right), \mathrm{T} 1\left(\mathrm{GA}_{3} 10^{-4} \mathrm{M}\right), \mathrm{T} 2(\mathrm{PBZ} 0.034 \mathrm{mM})$, T3 (PBZ $0.85 \mathrm{mM})$, T4 (PBZ $\left.0.034 \mathrm{mM}+\mathrm{GA}_{3} 10^{-4} \mathrm{M}\right)$ and T5 $\left(\mathrm{PBZ} 0.85 \mathrm{mM}+\mathrm{GA}_{3} 10^{-4} \mathrm{M}\right)$. Means followed by same letters are not significantly different by Tukey test $(\mathrm{P} \leq 0.05)$. 
$0,85 \mathrm{mM}$, ocorreram diminuições no comprimento $(52 \%)$, na largura $(60 \%)$ e no crescimento dos frutos $(70 \%)$, com base no valor da massa seca, em relação ao controle sem $\mathrm{GA}_{3}$ e paclobutrazol (figura 2). Comparando esses resultados àqueles obtidos quando os frutos foram tratados apenas com ácido giberélico, verificou-se que as reduções foram de $63 \%, 64 \%$, e $80 \%$, no comprimento, na largura e na massa seca dos frutos, respectivamente. Percebe-se, portanto que a produção de massa seca dos frutos foi mais afetada pelo paclobutrazol do que a largura e o comprimento. Uma vez que essa substância inibe a produção de giberelinas, possivelmente esse efeito pode ter sido causado pelo menor fluxo de sacarose aos frutos, pois, segundo Weaver et al. (1969), as giberelinas promovem um fluxo de nutrientes, dentre os quais, carboidratos, fundamentais para os frutos em crescimento. Isto indica que, possivelmente, as giberelinas endógenas produzidas nos frutos podem não ser suficientes para manter o crescimento, sendo necessário, portanto, o fornecimento de giberelinas de outras partes da planta.

Observa-se ainda na figura $2 \mathrm{~B}$ que a adição de paclobutrazol no meio de cultivo resultou na inibição da largura dos frutos, comparando-se os tratamentos contendo $0,034 \mathrm{mM}$ e $0,85 \mathrm{mM}$ de paclobutrazol ao tratamento sem paclobutrazol. A inibição foi mais acentuada na presença da maior concentração de paclobutrazol. Quando se aplicou $10^{-4} \mathrm{M}$ de $\mathrm{GA}_{3}$ conjuntamente com $0,034 \mathrm{mM}$ do inibidor da biossíntese de giberelinas, a largura dos frutos foi prontamente restaurada, equiparando-se ao tratamento controle sem o inibidor e ao tratamento com $10^{-4} \mathrm{M}$ de $\mathrm{GA}_{3}$ isoladamente. Isto sugere que as giberelinas estão envolvidas no crescimento de frutos imaturos de soja. A reversão não foi verificada na presença de $0,85 \mathrm{mM}$ de paclobutrazol, indicando que esse pode ter sido um nível fitotóxico para os frutos. Trabalhos semelhantes desenvolvidos por Santes et al. (1995) e GarciaMartinez et al. (1997), com frutos de ervilha em fase inicial de desenvolvimento, também demonstraram que o paclobutrazol inibiu o crescimento dos frutos, sendo esse efeito revertido pelo $\mathrm{GA}_{3}$. Esses autores relataram que o paclobutrazol reduziu acentuadamente o nível de giberelinas nos frutos, afetando seu crescimento.

Em relação ao comprimento (figura $2 \mathrm{~A}$ ) e a produção de massa seca (figura $2 \mathrm{C}$ ), observou-se o mesmo padrão de comportamento. Na presença de $10^{-4} \mathrm{M}$ de $\mathrm{GA}_{3}$ no meio de cultivo, o paclobutrazol na concentração de $0,85 \mathrm{mM}$ não causou reversão. Isso ocorreu apenas em 0,034 $\mathrm{mM}$ de paclobutrazol e em comparação ao tratamento $\operatorname{com} 10^{-4} \mathrm{M}$ de $\mathrm{GA}_{3}$ isoladamente.

A adição de glutamina, asparagina ou alantoína ao meio de cultivo promoveu aumento no comprimento dos frutos (figura 3A), em relação ao controle "in vitro" (sem nitrogênio). Entretanto, a fonte de nitrogênio não influenciou o tamanho das vagens, indicando que, para o comprimento dos frutos, no estádio de desenvolvimento utilizado, as fontes nitrogenadas empregadas foram igualmente eficientes. O mesmo padrão de comportamento foi obtido para a largura dos frutos (figura 3B), ou seja, todos os aminoácidos utilizados promoveram o crescimento em largura das vagens.

Todas as fontes de nitrogênio foram efetivas para incrementar o acúmulo de massa seca das vagens. A glutamina e a asparagina proporcionaram as maiores quantidades, seguida da alantoína (figura 3C). Apesar de não haver diferença significativa, a glutamina induziu a um incremento na massa seca dos frutos superior ao da asparagina, o qual alcançou $92 \%$, comparando-se com o crescimento dos legumes cultivados sem nitrogênio. Esses resultados, possivelmente, refletem o comportamento da planta intacta, pois, embora a planta de soja não transporte grandes quantidades de glutamina, esta é a principal fonte de nitrogênio utilizada durante o crescimento dos frutos (Hsu et al. 1984). Rainbird et al. (1984) verificaram que o crescimento de embrião de soja cultivado "in vitro" é muito lento em meio de cultura suplementado com ureídeos, no entanto, é rápido quando a fonte de nitrogênio utilizada é a glutamina ou a asparagina. A glutamina é a fonte de nitrogênio mais eficiente para o acúmulo de massa seca em cotilédones imaturos de soja, seguida da asparagina e alantoína (Haga \& Sodek 1987). Junghans \& Mosquim (1995) também verificaram incrementos na massa seca de sementes de soja, empregando asparagina, glutamina e alantoína como fontes de nitrogênio. Em outras espécies, como trigo, na ausência de uma fonte nitrogenada, o acúmulo de massa seca é drasticamente reduzido, podendo inclusive ser nulo (Barlow et al. 1983).

A atividade da GS foi sempre superior às atividades da NADH-GOGAT e Fd-GOGAT, independentemente da fonte de nitrogênio e da presença do ácido giberélico (tabela 1). Isso permite sugerir que, no estádio de desenvolvimento utilizado, os frutos estavam incorporando amônio em compostos orgânicos, visto que a GS é considerada a via principal de assimilação desse íon. Segundo Junghans \& Mosquim (1995), os quais também verificaram elevada atividade da GS em frutos 

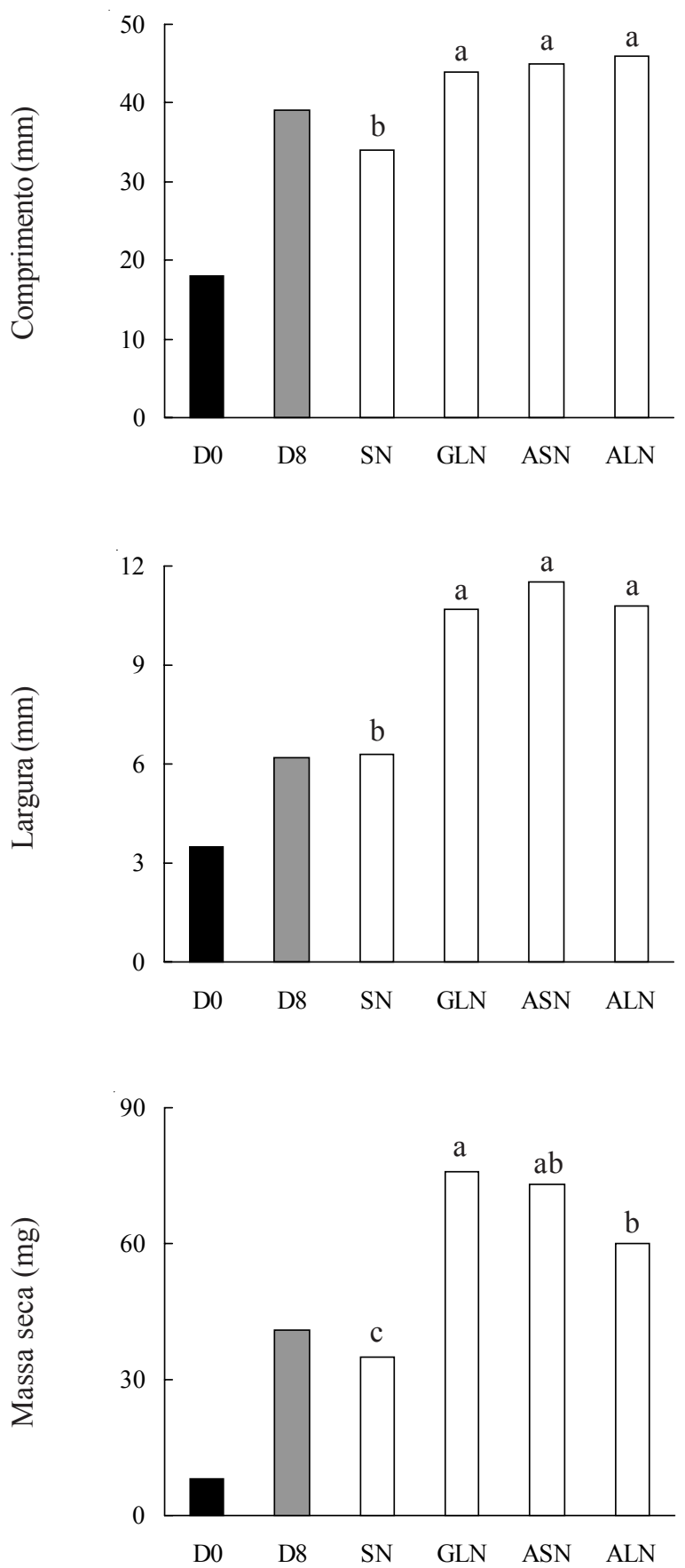

Figura 3. Efeito da glutamina (GLN), asparagina (ASN) e alantoína (ALN) sobre o comprimento (A), a largura (B) e a massa seca $(\mathrm{C})$ de frutos de soja. D0 (controle dia 0 ), D8 (controle dia 8) e SN (sem nitrogênio). Médias seguidas de uma mesma letra não diferem entre si pelo teste de Tukey $(\mathrm{P} \leq 0,05)$.

Figure 3. Effect of the glutamine (GLN), asparagine (ASN) and allantoin (ALN) on the length (A), width (B) and dry matter (C) in soybean fruit. D0 (control day 0), D8 (control day 8 ) and SN (without nitrogen). Means followed by same letters are not significantly different by Tukey test $(\mathrm{P} \leq 0.05)$.
A de soja, isso seria decorrente da incorporação inicial do amônio proveniente da degradação da asparagina e alantoína, por meio da ação das enzimas asparaginase e alantoínase, respectivamente. As atividades dessas enzimas foram detectadas em frutos de soja por Gomes \& Sodek (1984).

A alantoína induziu as maiores atividades para as três enzimas avaliadas (tabela 1). Isso, provavelmente, ocorreu em função da maior liberação de amônio, pois a alantoína possui quatro átomos de nitrogênio, ao passo que a glutamina e asparagina, apenas dois. Amônio é liberado durante o catabolismo da alantoína, entrando na via de assimilação do nitrogênio, por meio do sistema GS/GOGAT. Verifica-se, portanto, que o ureídeo alantoína foi mais eficiente do que a glutamina e asparagina para a atuação da GS. O produto da atividade dessa enzima, a glutamina, é utilizado como substrato da GOGAT. Assim, as atividades da GS e da GOGAT foram maiores na presença da alantoína nos frutos de soja em fase inicial de desenvolvimento.

$\mathrm{O}$ ácido giberélico inibiu a atividade da GS na presença de quaisquer das fontes de nitrogênio orgânico utilizadas. Isso permite sugerir que, em vagens no início do crescimento, a GS pode ter sua atividade modulada negativamente por aquele regulador de crescimento, na concentração utilizada $\left(10^{-4} \mathrm{M}\right)$ ou esta concentração pode ter causado a inibição. Alguns experimentos demonstram que os fitormônios influenciam o metabolismo do nitrogênio através de alterações na atividade das enzimas relacionadas, como a nitrato redutase, nitrito redutase, GS e GOGAT. Goupil et al. (1997) verificaram que a atividade da nitrato redutase foi maior em meio contendo $10^{-7} \mathrm{M}$ de ácido abscísico. Concentrações superiores inibiram a atividade da enzima.

A atividade da Fd-GOGAT e NADH-GOGAT foi estimulada por $\mathrm{GA}_{3}$. Provavelmente, essa giberelina regula a atividade dessas enzimas, estimulando-as. A atividade da Fd-GOGAT foi acentuadamente maior do que da NADH-GOGAT. Nos frutos crescendo sob iluminação ocorre atividade fotossintética, fonte de ferredoxina reduzida, a qual serve como doador de elétrons para a atividade da Fd-GOGAT. Isso, provavelmente, permitiu a maior atividade enzimática da Fd-GOGAT quando em comparação com a atividade da NADH-GOGAT.

Conclui-se, portanto, que giberelinas são, provavelmente, fundamentais para o crescimento de frutos imaturos de soja e estão envolvidas na regulação das atividades das enzimas glutamina sintetase e glutamato sintase nesses frutos. 
Tabela 1. Efeitos da glutamina, asparagina e alantoína, quando aplicadas em conjunto com ácido giberélico (+GA) ou na ausência dele (-GA), sobre a atividade da sintetase da glutamina (GS), sintase do glutamato dependente de ferredoxina (FdGOGAT) e sintase do glutamato dependente de NADH (NADH-GOGAT). Médias seguidas de uma mesma letra em cada coluna (minúscula) e em cada linha (maiúscula) não diferem entre si pelo teste de Tukey $(\mathrm{P} \leq 0,05)$.

Table 1. Effects of the glutamine, asparagine and allantoin, with (+GA) or without (-GA) gibberellic acid, on the activities of glutamine synthetase (GS) and glutamate synthase dependent of the ferredoxin (Fd-GOGAT) and glutamate synthase dependent of the NADH (NADH-GOGAT). Means followed by the same letter for each columm (small letters) and for each row (capital letters) are not significantly different by Tukey test $(\mathrm{P} \leq 0.05)$.

\begin{tabular}{|c|c|c|c|c|c|c|}
\hline & \multicolumn{2}{|c|}{$\frac{\mathrm{GS}}{\left(\mu \mathrm{mol} \mathrm{GHA} \cdot \mathrm{h}^{-1} \cdot \mathrm{g} \mathrm{MF}^{-1}\right)}$} & \multicolumn{2}{|c|}{$\frac{\text { Fd-GOGAT }}{\left(\mu \mathrm{mol} \mathrm{Glu} \cdot \mathrm{h}^{-1} \cdot \mathrm{g} \mathrm{MF}^{-1}\right)}$} & \multicolumn{2}{|c|}{$\frac{\text { NADH-GOGAT }}{\left(\mu \mathrm{mol} \mathrm{NAD}{ }^{+} \cdot h^{-1} \cdot \mathrm{g} \mathrm{MF}^{-1}\right)}$} \\
\hline & - GA & $+\mathrm{GA}$ & - GA & + GA & - GA & + GA \\
\hline Glutamina & $156 \mathrm{Ab}$ & $76 \mathrm{Bb}$ & $26,5 \mathrm{Bb}$ & $38,8 \mathrm{Ab}$ & $0,05 \mathrm{Bb}$ & $0,08 \mathrm{Ab}$ \\
\hline Asparagina & $108 \mathrm{Ac}$ & $71 \mathrm{Bb}$ & $22,5 \mathrm{Ac}$ & 24,3 Ac & $0,04 \mathrm{Bc}$ & $0,10 \mathrm{Ab}$ \\
\hline Alantoína & $161 \mathrm{Aa}$ & $127 \mathrm{Ba}$ & $36,5 \mathrm{Ba}$ & $63,5 \mathrm{Aa}$ & $0,11 \mathrm{Ba}$ & $0,22 \mathrm{Aa}$ \\
\hline
\end{tabular}

\section{Referências bibliográficas}

BARENDSE, G.W., KEPCZYNSKI, J., KARSSEN, C.M. \& KOORNNEFF, M. 1986. The role of endogenous gibberellins during fruit and seed development: studies on gibberellin-deficient genotypes of Arabidopsis thaliana. Physiologia Plantarum 67:315-319.

BARLOW, E.W.R., DONOVAN, G.R. \& LEE, J.W. 1983. Water relations and composition of wheat ears grown in liquid culture: effect of carbon and nitrogen. Australian Journal of Plant Physiology 10:99-108.

CHANDA, S.V., SOOD, C.R., REDDY, V.S. \& SINGH, Y.D. 1998. Influence of plant growth regulators on some enzymes of nitrogen assimilation in mustard seedlings. Journal of Plant Nutrition 21:1765-1777.

CHANDLER, P.M., HIGGINS, T.J.V., RANDALL, P.J. \& SPENCER, D. 1983. Regulation of legumin levels in developing pea seeds under conditions of sulfur deficiency. Plant Physiology 71:47-54.

GARCIA-MARTINEZ, J.L., LOPEZ-DIAZ, I., SANCHEZBELTRAN, M.J., PHILLIPS, A.L., WARD, D.A., GASKIN, P. \& HEDDEN, P. 1997. Isolation and transcript analysis of gibberellin 20-oxidase genes in pea and bean in relation to fruit development. Plant Molecular Biology 33:1073-1084.

GARCIA-MARTINEZ, J.L., SPONSEL, V.M. \& GASKIN, P. 1987. Gibberellins in developing fruits of Pisum sativum cv. Alaska: studies on their role in pod growth and seed development. Planta 170:130-137.

GLASS, A.D.M., BRITTO, D.T., KAISER, B.N., KINGHORN, J.R., KRONZUCKER, H.J., KUMAR, A., OKAMOTO, M., RAWAT, S., SIDDIQI, M.Y., UNKLES, S.E. \& VIDMAR, J.J. 2002. The regulation of nitrate and ammonium transport systems in plants. Journal of Experimental Botany 53:855-864.

GOMES, M.A.F. \& SODEK, L. 1984. Allantoinase and asparaginase activities in maturing fruits of nodulated and non-nodulated soybeans. Physiologia Plantarum 62:105-109.
GRAEBE, J.E. 1987. Gibberellin biosynthesis and control. Annual Review of Plant Physiology 38:419-465.

GREGERSON, R.G., MILLER, S.S. \& TWARY, S.N. 1993. Molecular characterization of NADH-dependent glutamate synthase from alfafa nodules. Plant Cell 5:215-226.

HAGA, K.I. \& SODEK, L. 1987. Utilization of nitrogen sources by immature soybean. Annals of Botany 59:597-601.

HAÜSSLER, R.E., BLACKWELL, R.D. \& LEA, P.J. 1994. Control of photosynthesis in barley leaves with reduced activities of glutamine synthetase or glutamate synthase. I. Plant characteristics and changes in nitrate, ammonium and amino acids. Planta 194:406-417.

HOAGLAND, D.R. \& ARNON, D.I. 1938. The water culture method for growing plants without soil. Circular 347. University of California College of Agriculture, Berkeley.

HOOLEY, R. 1994. Gibberellins: perception, transduction and responses. Plant Molecular Biology 26:1529-1555.

HSU, F.C., BENNET, A.B. \& SPANSWICK, R.M. 1984. Concentrations of sucrose and nitrogenous compounds in the apoplast of developing soybean seed coats and embryos. Plant Physiology 75:181-186.

JUNGHANS, T.G. \& MOSQUIM, P.R. 1995. Atividade da sintetase da glutamina e sintase do glutamato em explantes de frutos de soja sob diferentes fontes de nitrogênio. Revista Brasileira de Fisiologia Vegetal 71:67-74.

LANGE, T. 1998. Molecular biology of gibberellin synthesis. Planta 204:409-419.

MOSQUIM, P.R. \& SODEK, L. 1991. Culture of soybean fruit explants: growth conditions and efficiency of nitrogen sources for reserve protein synthesis. Plant Cell, Tissue and Organ Culture 27:71-76.

PEAT, L.J. \& TOBIN, A.K. 1996. The effect of nitrogen nutrition on the cellular localization of glutamine synthetase isoforms in barley roots. Plant Physiology 111:1109-1117. 
RAINBIRD, R.M., THORNE, J.H., HARDY, R.W.F. 1984. Role of amides, aminoacids, and ureides in the nutrition of developing soybean seeds. Plant Physiology 74:329-334.

RHODES, D., RENDON, G.A., STEWART, G.R. 1975. The control of glutamine synthetase level in Lemna minor L. Planta 125:201-211.

RODRIGO, M.J., GARCIA-MARTINEZ, J.L., SANTES, C.M., GASKIN, P. \& HEDDEN, P. 1997. The role of gibberellins $\mathrm{A}_{1}$ and $\mathrm{A}_{3}$ in fruit growth of Pisum sativum $\mathrm{L}$. and the identification of gibberellins $\mathrm{A}_{4}$ and $\mathrm{A}_{7}$ in young seeds. Planta 201:446-455.

SANTES, C.M., HEDDEN, P., GASKIN, P. \& GARCIAMARTINEZ, J.L. 1995. Gibberellins and related compounds in young fruits of pea and their relationship to fruit-set. Phytochemistry 40:1347-1355.

SCHRADER, L.E. \& THOMAS, R.J. 1981. Nitrate uptake, reduction and transport in the whole plant. In Nitrogen and carbon metabolism (J.D. Bewley, ed.). Plenum Press, New York, p.49-93.

SCHULLER, K.A., DAY, D.A. \& GIBSON, A.H. 1986. Enzymes of ammonia assimilation and ureide biosynthesis in soybean nodules: effect of nitrate. Plant Physiology 80:646-650.
STEPHEN, M., SWAIN, J.B.R. \& KAMIYA, Y. 1997. Gibberellins are required embryo growth and seed development in pea. The Plant Journal 12:1329-1338.

STERRET, J.P. 1985. Paclobutrazol: a promising growth inhibitor for injection into woody plants. Journal of the American Society of Horticultural Science 110:4-8.

THOMPSON, J.F., MADISON, J.T. \& MUENSTER, A.M.E. 1977. In vitro culture of immature cotyledons of soybean (Glycine max (L.) Merr.). Annals of Botany 41:29-39.

TONIN, G.S. 1988. Influência da fonte de nitrogênio na atividade de enzimas envolvidas no processo de assimilação de amidas e ureídeos em cotilédones imaturos de soja mantidos em cultura. Tese de doutorado, Universidade Estadual de Campinas, Campinas.

VAN HUIZEN, R., OZGA, J.A. \& REINECKE, D.M. 1997. Seed and hormonal regulation of gibberellins 20-oxidase expression in pea pericarp. Plant Physiology 115:123-128.

WANG, S.Y., SUN, T. \& FAUST, M. 1986. Translocation of paclobutrazol, a gibberellin biosynthesis inhibitor, in apple seedling. Plant Physiology 82:11-14.

WEAVER, R.J., SHINDY, W. \& KLIEWER, M.W. 1969. Growth regulator induced movement of photosynthetic products into fruits of Black grapes. Plant Physiology 44:183-188. 